\title{
Controlled Penetration of a Novel Dimeric Ceramide into and across the Stratum Corneum Using Microemulsions and Various Types of Semisolid Formulations
}

\author{
Reinhard H.H. Neubert ${ }^{a}$ b Stefan Sonnenberger ${ }^{a, c}$ Bodo Dobner ${ }^{c}$ \\ Charles W. Gray Jr. ${ }^{f} \quad$ K. Natalie Barger ${ }^{f} \quad$ Kara Sevi-Maxwell $^{f} \quad$ Elfi Sommer $^{\mathrm{e}}$ \\ Johannes Wohlraba, d \\ ${ }^{\mathrm{a}}$ Institute of Applied Dermatopharmacy, Departments of ${ }^{\mathrm{b}}$ Pharmaceutical Technology and Biopharmaceutics and \\ 'Pharmaceutical Chemistry and Clinical Pharmacy, Institute of Pharmacy, and d Department of Dermatology and \\ Venereology, Medical Faculty, Martin Luther University Halle-Wittenberg, and ' Skinomics GmbH, Halle (Saale), \\ Germany; ${ }^{f} \mathrm{Ei}$, A Pharmaceutical Solutionworks, Kannapolis, N.C., USA
}

\section{Key Words}

Novel dimeric ceramide Stabilizer of the stratum corneum barrier · Penetration into human skin · Colloidal and semisolid formulations · Franz diffusion cell · Liquid chromatography/atmospheric-pressure ionization/mass spectrometry

\footnotetext{
Abstract

Ceramides (CERs) are integral parts of the intercellular lipid lamellae of the stratum corneum (SC), which is responsible for the barrier function of the skin. Many skin diseases such as atopic dermatitis and psoriasis are associated with the depletion or disturbance of the level of CERs in the SC. Administration of an exogenous novel dimeric ceramide (dCER) deep into the SC may help to stabilize the SC barrier substantially and to treat some skin disease conditions. Consequently, with the help of the existing technology, it might be possible to formulate various pharmaceutical dosage forms that can facilitate penetration of dCER into the SC. Therefore, the penetration of dCER was studied using a high-performance liquid chromatography/atmospheric-pressure ionization/
}

mass spectrometry method for the detection and quantification of exogenous dCER in the SC as well as other skin layers. Penetration studies were carried out in the Franz diffusion cell using excised human skin ex vivo. Penetration of dCER was studied with 3 model formulations: a colloidal formulation (microemulsion), a cream formulation with ethoxydiglycol as penetration enhancer and a nanoformulation. The highest concentrations of dCER in the different skin layers were found after application of the cream with penetration enhancer. Surprisingly, the lowest concentrations of dCER in the different skin layers were found after application of the microemulsion.

(c) 2016 S. Karger AG, Basel

\section{Introduction}

Ceramides (CERs) are integral parts of the intercellular lipid lamellae of the stratum corneum (SC), which is responsible for the barrier function of the mammalian skin [1-6]. Many skin disease conditions, such as psoriasis [7], atopic dermatitis [8-10] and irritant/allergic con-

\section{KARGER}

E-Mail karger@karger.com

www.karger.com/spp (c) 2016 S. Karger AG, Base

$1660-5527 / 16 / 0293-0130 \$ 39.50 / 0$
Prof. Dr. Dr. h.c. Reinhard H.H. Neubert

Institute of Applied Dermatopharmacy, Martin Luther University Halle-Wittenberg Weinbergweg 23

DE-06120 Halle (Saale) (Germany)

E-Mail reinhard.neubert@pharmazie.uni-halle.de 
Fig. 1. dCER molecule structural formula.

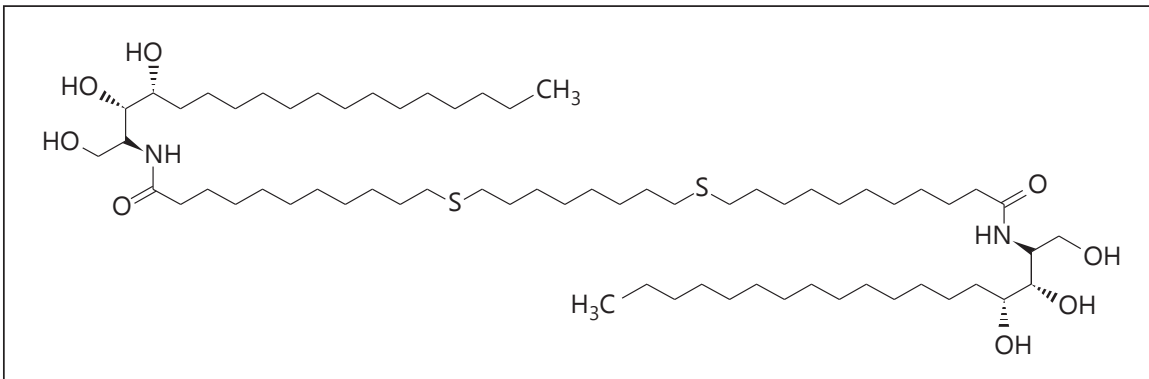

tact dermatitis [11], are associated with depletion or disturbance of the level of CERs in the SC. Therefore, incorporation of a novel dimeric ceramide (dCER; fig. 1) into the lipid lamellae of the SC might help to stabilize the SC and to treat such skin conditions. Molecules for stabilizing the SC lipids are highly desired in dermatopharmacy and cosmetics [12].

Penetration of short-chain ceramides such as CER NP has already been studied in the literature [13]. In the past, colloidal carrier systems such as microemulsions were developed to carry CER NP into the SC $[14,15]$. However, the incorporation of such a rigid and extremely lipophilic molecule such as dCER, which is practically insoluble in most of the pharmaceutically relevant solvents in formulations, is a real challenge [16].

Therefore, the aim of this work was to incorporate the novel dCER (fig. 1) into colloidal and semisolid formulations and to study the penetration of dCER from these formulations into human skin ex vivo. A Franz diffusion cell and a sensitive and selective liquid chromatography/ atmospheric-pressure ionization-mass spectrometry (LC/APCI-MS) method were used to study the penetration of CER in SC and other skin layers.

\section{Materials and Methods}

\section{Materials}

Carbamazepine was obtained from Sigma-Aldrich (St. Louis, Mo., USA). Hydrolite 5 (pentylene glycol) was from Symrise AG (Holzminden, Germany), isopropylpalmitate from Caesar \& Loretz GmbH (Hilden, Germany), sucrose laurate L 595 from Mitsubishi-Kagaku Foods Corporation (Tokyo, Japan), Tego Care PL4 (polyglyceryl-4-laurate) from Evonik Industries AG (Essen, Germany). Ethanol, isopropanol, chloroform and n-heptane were obtained from Carl Roth GmbH and Co. KG (Karlsruhe, Germany). Transcutol (ethoxydiglycol) was from Gattefosse Corporation (Paramus, N.J., USA).

\section{Methods}

Characterization of dCER

dCER Synthesis. The synthesis of 12,21-dotriacontanedioic acid (compound 1) is described in detail in the literature [17]. Preparation of the N,N'-bis[(2S,3S,4R)-1,3,4-trihydroxyoctadec2-yl]-12,21-dithiadotriacontanediamide (compound 2) was as follows: to a suspension of $7 \mathrm{mmol}$ ( $3.83 \mathrm{~g}$ ) of compound 1 in 300 $\mathrm{ml} \mathrm{CH} \mathrm{Cl}_{2}$ was added under stirring $14.7 \mathrm{mmol}(7.65 \mathrm{~g}$ ) of Py$\mathrm{BOP}^{\circledR}$ and $28 \mathrm{mmol}(4.76 \mathrm{ml})$ of diisopropylethylamine. The mixture was stirred for $20 \mathrm{~min}$ at room temperature. After that 14.7 mmol (4.67 g) phytosphingosine was added to the solution. The stirring was continued for $16 \mathrm{~h}$ at the same temperature. The precipitate was filtered off, and the filter was washed twice with $15 \mathrm{ml}$ $\mathrm{CH}_{2} \mathrm{Cl}_{2}$. The crude CER was purified by column chromatography using chloroform/methanol/ammonia as eluent.

Solubility of dCER. dCER is practically unsoluble $(<0.1 \mathrm{~g} / \mathrm{l})$ in propylene glycol, 1,2-pentylene glycol, glycerol, isopropylpalmitate, dimethylsulfoxide, 2-pyrrolidone, polyglyceryl-6-ricinoleate, ethoxydiglycol (Transcutol) and polyglyceryl-3-caprate according to the European Pharmacopeia.

High-Performance Liquid Chromatography/

Atmospheric-Pressure Ionization-Mass Spectrometry

The development and validation of a quantification method for dCER was performed by means of HPLC system Agilent Technologies 1220 (Agilent Technologies, Waldbronn, Germany) equipped with an autosampler. A normal-phase HPLC column, Zorbax RX-SIL Agilent $2.1 \times 150$ mm, $5 \mu \mathrm{m}$, PN 883700-901, SN USK1002248 (Agilent Technologies, USA), was used as stationary phase. The mobile phase consists of solvent A [n-heptane/isopropanol 95:5 (v/v)] and solvent B [n-heptane/isopropanol/ethanol 50:25:25 (v/v/v)]. The following gradient elution mode was applied: 0 min $100 \%$ solvent A; 15 min $25 \%$ solvent A, $75 \%$ solvent B; 16 min $100 \%$ solvent B; 20 min $100 \%$ solvent B; 21 min $100 \%$ solvent A. Stop time of the gradient was set at $28 \mathrm{~min}$ with $1 \mathrm{~min}$ of posttime. A flow rate of $0.4 \mathrm{ml} / \mathrm{min}$ was chosen till the 16 th $\mathrm{min}$ of the gradient. Afterwards a $0.6 \mathrm{ml} / \mathrm{min}$ flow rate was used for a proper washing of the column and faster backequilibration to the starting parameters. The maximum pressure was set to 400 bar. The injection volume and the temperature of the column were 10 $\mu \mathrm{l}$ and $30^{\circ} \mathrm{C}$, respectively. The Agilent OPENLAB software for HPLC was applied.

An MS detector Infinity LC MS-System/LCQ (Thermo Finnigan AG, Waldbronn, Germany) was used for quantification of dCER after chromatographic separation. The detector was set to 
positive APCI [+APCI) mode; source heat temperature $500^{\circ} \mathrm{C}$, sheath gas flow rate 70 arb (Air Resources Board units), auxiliary gas flow rate $10 \mathrm{arb}$, discharge current $7 \mu \mathrm{A}$, capillary temperature $200^{\circ} \mathrm{C}$, capillary voltage $3 \mathrm{~V}$ and tube lens offset at $15 \mathrm{~V}$ ]. $\mathrm{N}_{2}$ was used as nebulizer and as drying gas.

The Xcalibur 2.0 software was used for MS spectra recording and evaluation. A special layout for the evaluation of the obtained data was developed:

1 full scan with base peak F: + APCI corona full scan MS (100.002,000.00);

2 CBZ SIM $\mathrm{m} / \mathrm{z}=236.77-237.77 \mathrm{~F}$ : +APCI corona SIM MS (236.2-238.2, 1,144.00-1,148.00);

3 DC SIM $\mathrm{m} / \mathrm{z}=1,145.39-1,146.39 \mathrm{~F}$ : +APCI corona SIM MS (236.2-238.2, 1,144.00-1,148.00).

The limit of detection was $0.167 \mu \mathrm{g} / \mathrm{ml}$, and the limit of quantification (LOQ) was $0.334 \mu \mathrm{g} / \mathrm{ml}$. Precision of the methods was relative standard deviation $<15 \%$ for the LOQ [18].

Formulations

The penetration of the dCER was studied from the following formulations:

- a microemulsion (ME-145 1a) with 0.2\% dCER was used for the penetration study; it was prepared by Skinomics $\mathrm{GmbH}$ (Halle/Saale, Germany);

- a cream formulation (Ei LLC) with 1.0\% dCER was used with $10 \%$ ethoxydiglycol (Transcutol P); it was prepared by Ei, A Pharmaceutical Solutionworks (Kannapolis, N.C., USA);

- a nanoformulation (Med Drop) with 1.0\% dCER was used; it was prepared by ValeoPharm GmbH (Hamburg, Germany).

\section{Penetration Studies}

Penetration studies were carried out on human cadaver skin. The tissue sections were postoperatively cleaned with mull pads and isotonic $\mathrm{NaCl}$ solution. The subcutaneous adipose tissue was mechanically dissected and discarded. Circular pieces of skin (20 $\mathrm{mm}$ in diameter, $3.14 \mathrm{~cm}^{2}$ ) were punched, hermetically sealed in tin foil, packed in an occlusive polyethylene bag and stored at $-20^{\circ} \mathrm{C}$.

The investigations were performed in glass Franz diffusion cells (Crown Glass Company Inc., Somerville, N.Y., USA) (fig. 2). Water was used as the acceptor since salts from buffer solution would obstruct the analysis by HPLC/MS. At the time of the investigation the pieces of skin were completely defrosted at room temperature, and the surface was dried using cotton pads.

In the following, $20 \mathrm{mg}$ of the formulation were applied to the individual skin specimens located on filter gauze (Sartolon polyamide, pore size $0.45 \mu \mathrm{m}$; Sartorius Stedim Biotech $\mathrm{GmbH}$, Göttingen, Germany). The specimens were stretched on the diffusion cell that was preheated to $32^{\circ} \mathrm{C}$, therefore enabling the underside of the skin with the filter gauze to contact directly the acceptor medium which was continuously stirred in order to reduce the thickness of the diffusion layer. Thus, the preconditions for removal of amounts of permeated active substance were ensured and physiological conditions were simulated. The system was protected from evaporation losses without creating occlusive conditions by a glass cover, which was lying loose on the surface. Skin specimens of 1 donor and an application period of $100 \mathrm{~min}$ were investigated. To determine the amounts of penetrated active substance during the respective application period, the skin specimens were taken out of the diffusion cell, and the remaining preparations (residues) were carefully removed from the surface using a cotton pad. Sub-

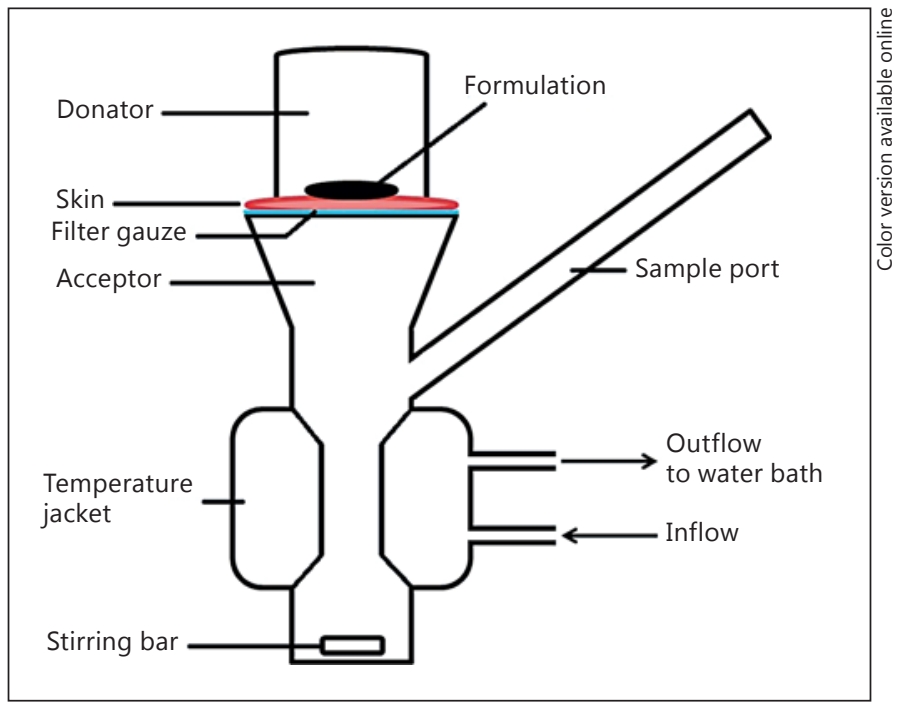

Fig. 2. Franz diffusion cell.

Table 1. Preparation of the penetration samples

\begin{tabular}{lll}
\hline Sample & Medium & $\begin{array}{l}\text { Extraction } \\
\text { volume/ } \\
\text { preparation }\end{array}$ \\
\hline Nonpenetrated residue & swab & $\begin{array}{l}20 \mathrm{ml} \text {, then } \\
\text { diluted } 1: 100\end{array}$ \\
Upper SC (SC1) & 1 section at $10 \mu \mathrm{m}$ & $0.2 \mathrm{ml}$ \\
Lower SC (SC2) & 1 section at $10 \mu \mathrm{m}$ & $0.2 \mathrm{ml}$ \\
Viable epidermis (EP1) & 2 sections at $20 \mu \mathrm{m}$ & $0.2 \mathrm{ml}$ \\
Viable epidermis (EP2) & 2 sections at $20 \mu \mathrm{m}$ & $0.2 \mathrm{ml}$ \\
Dermis 1 (DR1) & 5 sections at $40 \mu \mathrm{m}$ & $0.2 \mathrm{ml}$ \\
Dermis 2 (DR2) & 5 sections at $40 \mu \mathrm{m}$ & $0.2 \mathrm{ml}$ \\
Dermis 3 (DR3) & 5 sections at $40 \mu \mathrm{m}$ & $0.2 \mathrm{ml}$ \\
Stump & residual skin & $0.2 \mathrm{ml}$ \\
Permeated amount & filter gauze & $2 \mathrm{ml}$ \\
Permeated amount & acceptor fluid & $1 \mathrm{ml}$ evaporated \\
& & to $100 \mu \mathrm{l}$ \\
\hline
\end{tabular}

sequently the skin was cut into 4 pieces. In order to determine the concentration profile, the individual skin layers were separated horizontally by a cryomicrotome at $-40^{\circ} \mathrm{C}$ (Fa. Jung, Heidelberg, Germany) as described in table 1.

\section{Results and Discussion}

The novel dCER is practically insoluble in most of the relevant pharmaceutical solvents and excipients (see the section 'Characterization of dCER'). Therefore, it is chal- 


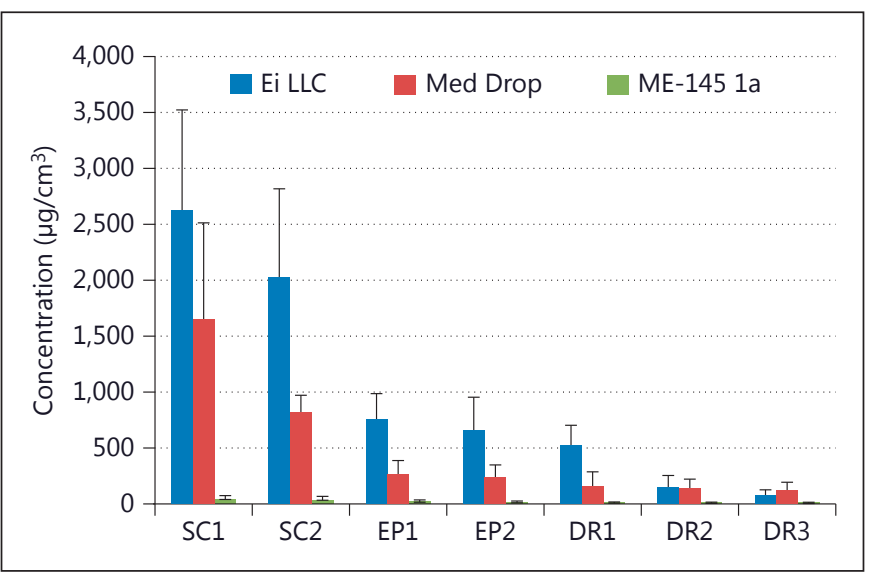

Fig. 3. Concentration of dCER penetrated from the three investigated formulations. $\mathrm{EP}=$ Epidermis; $\mathrm{DR}=$ dermis (penetration time $=100 \mathrm{~min} ; \mathrm{n}=4$ )

lenging to incorporate dCER into pharmaceutical formulations which are able to carry this molecule into the SC.

Three formulations were used for the incorporation of dCER. Firstly, a colloidal formulation (microemulsion) was applied which was already used in order to carry CER NP into the human SC $[13,14]$. Unfortunately, just $0.2 \%$ of the dCER could be incorporated into this microemulsion. Secondly, a cream formulation was applied which contains $10 \%$ ethoxydiglycol as penetration enhancer. Thirdly, a nanoformulation was used which was developed by ValeoPharm GmbH.

A sensitive, accurate, repeatable, robust and selective LC/APCI-MS method was used for the quantification of exogenous dCER in the SC and deeper layers of the skin. This analytical method with a LOQ of $0.334 \mu \mathrm{g} / \mathrm{ml}$ was sensitive enough in order to measure the penetration of dCER from the mentioned formulations into the SC as well as deeper layers of the human skin.

The penetration studies were carried out using the Franz diffusion cell (fig. 2) and human cadaver skin. The results of the penetration studies are shown in figure 3 .

After application of the microemulsion, the lowest concentration of dCER in the SC as well as in deeper layers of the viable epidermis and of the dermis was obtained. This result underlines that the microemulsion is not suitable to carry dCER into the SC, maybe because of the small amount of dCER which could be incorporated into this formulation $(0.2 \%)$.

The nanoformulation Med Drop shows moderate concentrations (maximum around $1,500 \mu \mathrm{g} / \mathrm{cm}^{3}$ ) of dCER in all skin layers.

Penetration of Dimeric Ceramide
From all three investigated formulations, the highest concentration of dCER in the SC as well as in deeper layers of the viable epidermis and of the dermis was measured after application of the cream (Ei LLC). It appears the dCER was incorporated into the lamellar structures of the cream. Therefore, this cream formulation is a suitable formulation for carrying a rigid and extremely lipophilic molecule such as dCER into the human SC.

No dCER was detected in acceptor media of the Franz diffusion cell after the application of all formulations used in this penetration study. This result indicates that there is no dCER available for potential systemic absorption of this molecule after application of the dCER in the three formulations studied.

Currently, studies are running in order to evaluate the influence of dCER on the nanostructure of SC lipid model membranes.

\section{Conclusion}

A novel dCER was synthesized in order to stabilize the SC barrier. A sensitive, accurate, repeatable, robust and selective LC/APCI-MS method was used for the quantification of exogenous dCER in the SC and deeper layers of the skin. The dCER was incorporated into three model formulations: a microemulsion, a nanoformulation, and a cream formulation containing ethoxydiglycol (Transcutol $\mathrm{P}$ ) as penetration enhancer.

The highest concentrations of dCER in the different skin layers were found after application of the cream with penetration enhancer.

Surprisingly, the concentrations of dCER found in the different skin layers were very low after application of the microemulsion.

No dCER was detected in acceptor media of the Franz diffusion cell after the application of all formulations used in this penetration study.

\section{Acknowledgments}

This work was supported by grants from the Deutsche Forschungsgemeinschaft (projects NE 427/30-1 and DO 463/6-1).

The authors would like to acknowledge Manuela Woigk, Institute of Pharmacy, MLU Halle-Wittenberg, Halle (Saale), and Anke Nies, Skinomics GmbH, Halle (Saale), for their excellent technical assistance during the experimental work. 


\section{Statement of Ethics}

The experiments were accepted by the Ethical Committee of the Martin Luther University Halle-Wittenberg.

\section{Disclosure Statement}

The authors have no conflicts of interest to disclose.

\section{References}

1 Wartewig S, Neubert RHH: Properties of ceramides and their impact on the stratum corneum structure - a review. 1. Ceramides. Skin Pharmacol Physiol 2007;20:220-229.

2 Stewart ME, Downing DT: A new 6-hydroxy4-sphingenine-containing ceramide in human skin. J Lipid Res 1999;40:1434-1439.

3 Masukawa Y, Narita H, Shimizu E, Kondo N, Sugai Y, Oba T, Homma R, Ishikawa J, Takag Y, Kitahara T, Takema Y, Kita K: Characterization of overall ceramide species in human stratum corneum. J Lipid Res 2008;49:1466-1476.

4 Mizutani Y, Mitsutake S, Tsuji K, Kihara A, Igarashi Y: Ceramide biosynthesis in keratinocyte and its role in skin function. Biochimie 2009;91:784-790.

5 Mutanu Jungersted J, Hellgren LI, Hogh JK, Drachmann T, Jemec GB, Agner T: Acta Derm Venereol 2010;90:350-353.

6 Lampe MA, Williams ML, Elias PM: Human epidermal lipids: characterization and modulations during differentiation. J Lipid Res 1983;24:131-140

7 Cho Y, Lew BL, Seong K, Kim NI: An inverse relationship between ceramide synthesis and clinical severity in patients with psoriasis. J Korean Med Sci 2004;19:859-863.
8 Berardesca E, Barbareschi M, Veraldi S, Pimpinelli N: Evaluation of efficacy of a skin lipid mixture in patients with irritant contact dermatitis, allergic contact dermatitis or atopic dermatitis: a multicenter study. Contact Dermatitis 2001;45:280-285.

9 Loden M: The skin barrier and use of moisturizers in atopic dermatitis. Clin Dermatol 2003;21:145-157.

10 Proksch E, Jensen JM, Elias PM: Skin lipids and epidermal differentiation in atopic dermatitis. Clin Dermatol 2003;12:134-144.

11 Sahle FF, Gebre-Mariam T, Dobner B, Wohlrab J, Neubert RHH: Skin diseases associated with the depletion of stratum corneum lipids and stratum corneum lipid substitution therapy. Skin Pharmacol Physiol 2015;28:42-55.

12 Trommer H, Neubert RHH: Overcoming the stratum corneum: the modulation of skin penetration. Skin Pharmacol Physiol 2006;19: 106-121.

13 Sahle FF, Wohlrab J, Neubert RHH: Controlled penetration of ceramides into and across the stratum corneum using various types of microemulsions and formulation associated toxicity studies. Eur J Pharm Biopharm 2014;86:244-250.
14 Sahle FF, Metz H, Wohlrab J, Neubert RHH Polyglycerol fatty acid ester surfactant-based microemulsions for targeted delivery of ceramide AP into the stratum corneum: formulation, characterisation, in vitro release and penetration investigation. Eur J Pharm Biopharm 2012;82:139-150.

15 Sahle FF, Metz H, Wohlrab J, Neubert RHH Lecithin-based microemulsions for targeted delivery of ceramide AP into the stratum corneum: formulation, characterizations, and in vitro release and penetration studies. Pharm Res 2013;30:538-551.

16 Neubert RHH: Potentials of new nanocarriers for dermal and transdermal drug delivery. Eur J Pharm Biopharm 2011;77:1-2.

17 Sonnenberger S: Ceramide-Dimer (Procedure of its synthesis and its application). US Patent, US Patent No 62/206,983. August 19, 2015.

18 Neubert RHH, Bayrak O, Steinbach S, Sonnenberger S, Dobner B: Development and validation of analytical methods for the detection and quantification of a novel dimeric ceramide in stratum corneum and other layers of the skin. J Pharm Biomed Anal, submitted. 